\title{
MEIOS DE SOLUÇÃO DIGITAL DE CONFLITOS - ONLINE DISPUTE RESOLUTION (ODR)
}

\author{
Bianca Santos Cavalli Almeida ${ }^{1}$ \\ Maíra de Oliveira Lima Ruiz Fujita*
}

\begin{abstract}
Resumo
O objetivo deste artigo é examinar meios de solução digital de conflitos, bem como analisar os possíveis benefícios ou desvantagens da utilização destes novos recursos ao invés da utilização de métodos tradicionais que requerem a reunião presencial entre as partes visando a negociação ou conciliação, entre outras hipóteses. Considerando a atual estrutura da Sociedade da Informação, aliada à Quarta Revolução Industrial, importante analisar a eficácia desta espécie de resolução de conflitos, bem como seus eventuais impactos no acesso à Justiça. Ainda, busca esclarecer o mecanismo da ODR, como instrumento ágil, econômico e simples para solução de conflitos em espaço virtual.
\end{abstract}

Palavras-chave: ODR (Online Dispute Resolution). Solução digital de conflitos. Sociedade da Informação. Acesso à Justiça.

\section{MEANS OF DIGITAL CONFLICT RESOLUTION - ONLINE DISPUTE RESOLUTION (ODR)}

\begin{abstract}
The objective of this article is to examine appropriate means of resolving conflicts in the information society, as well as analyzing the possible benefits or disadvantages of using these new resources instead of using traditional methods that require presential meeting between the parties in order to negotiate or conciliation, among other hypotheses. Considering the actual Information Society structure, allied to the Fourth Industrial Revolution, it is important to analyze the efficiency of this kind of conflict resolution, as well as its impacts on the access to Justice. It also seeks to clarify the mechanism of ODRs (Online Dispute Resolution), as an agile, economical and simple instrument for outcome of conflicts in virtual space.
\end{abstract}

Keywords: ODR (Online Dispute Resolution). Digital conflict solutions. Information society. E-commerce. Access to Justice.

\section{Introdução}

\footnotetext{
*Advogada e Mestranda no Programa de Mestrado em Direito da Sociedade da Informação, no Centro Universitário das Faculdades Metropolitanas Unidas - FMU. Bacharel em Direito pela Faculdade Mackenzie São Paulo. Especialista em Direito Empresarial pela Fappes/SP e em Direito Tributário pela Faculdade Damásio de Jesus/SP. biancacavallialmeida@gmail.com

* Advogada. Possui graduação em Direito pelo Centro Universitário das Faculdades Metropolitanas Unidas (2003). MBA em Direito Empresarial pela Fundação Getúlio Vargas - FGV/SP. Especialista em Direito Digital pela Fundação Getúlio Vargas - FGV/SP. Mestranda em Direito, área de concentração Sociedade da Informação, pelo Centro Universitário das Faculdades Metropolitanas Unidas - FMU. maira.limaruiz@ gmail.com
} 
Os conflitos de interesses são praticamente indissociáveis da convivência entre seres humanos em determinado ambiente ou comunidade. Durante o desenvolver da humanidade, surgiram diversas formas de solução de conflitos, algumas delas praticamente ditatoriais, que permitiam uma desigualdade entre os envolvidos. A partir o surgimento do Poder Judiciário estruturado, os conflitos passaram a contar um uma terceira parte imparcial, a qual seria responsável por encontrar a melhor solução para determinada contenda.

Nas últimas décadas, o Poder Judiciário foi o principal responsável pela análise da maioria dos conflitos de interesses e ante o crescente aumento de novas modalidades relações jurídicas, as quais também foram fomentadas pela Sociedade da Informação com o consequente aumento do consumismo, a carga das demandas não acompanhou o aumento da máquina estatal. Consequentemente, as soluções de conflitos deixaram de ser realizadas de maneira célere e eficaz, fato este sedimentado nas dificuldades estruturais e financeiras (JUNIOR, 2017, p. 267) aliadas ao grande aumento da demanda.

Considerando este cenário de assoberbamento do Poder Judiciário, o Conselho Nacional de Justiça - CNJ, criado em 2004 com a Reforma do Poder Judiciário, traçou algumas políticas públicas para incentivo dos chamados "Métodos Adequados de Solução de Conflitos - MASC", fomentando a mediação e a conciliação, bem como a virtualização do Poder Judiciário (LIMA, 2016, p. 54)

E nesta toada, de crescente desenvolvimento tecnológico, surgiram os chamados meios de solução online de conflitos, com o objetivo de desafogar o Poder Judiciário de causas de menor complexidade, de maneira a fomentar que matérias de menor potencial científico (ANDRIGHI, 2005, p. 7) sejam submetidos à caríssima máquina governamental.

O presente artigo tem como objetivo trazer um panorama da resolução online de conflitos no Brasil, além de especificar algumas formas pelas quais tais ferramentas são utilizadas na atualidade, bem como traçar uma análise desta atual modalidade em relação ao direito fundamental do acesso à Justiça, por meio de uma análise doutrinária e documental jurídica, com enfoque em entendimentos especializados e dados estatísticos relativos ao objeto deste estudo.

\section{Relevância do tema para ampliação do acesso ao Judiciário}


Primeiramente, importante destacar que com o intuito de evitar que uma grande quantidade de conflitos seja direcionada ao Poder Judiciário, sobrecarregando-o ainda mais com processos que poderiam ser resolvidos na esfera extrajudicial, por exemplo, cada vez mais empresas e consumidores vêm recorrendo às formas mais simples, econômicas e ágeis de resolução de disputas.

Neste sentido, urge salientar que conforme dados do Conselho Nacional de Justiça ${ }^{2}$, em sua publicação "Justiça em números 2018”, o tempo médio de baixa de processo em primeira instância por exemplo, é de aproximadamente três anos e, no caso de execução judicial em primeiro grau, o prazo pode alcançar quatro anos. Assim, estimular a conciliação pré-processual se apresenta como significativa contribuição para se reduzir o referido índice.

Conforme anteriormente exposto, o conflito inerente às relações sociais e as alterações na forma de interação entre as pessoas na atual Sociedade da Informação, que cada vez mais se relaciona no ambiente líquido (BAUMAN, 2008, p. 15), influencia diretamente a formação de divergências (MAGALHÃES e SARAIVA, 2019, p. 03). Segundo esclarece Fernando Amorim em obra sobre a resolução online de litígios, o desenvolvimento tecnológico relativo à transmissão de dados e de informação alterou definitivamente a forma como os indivíduos se relacionam, repercutindo, ainda, nas relações jurídicas que passam a ser estabelecidas também no ciberespaço (AMORIM, 2017, p.515).

$\mathrm{O}$ autor indica ainda que "as relações jurídicas firmadas no ciberespaço instauram uma nova forma de relacionamento com o real, criando outras fontes de normatividade, exigindo do Direito uma revisão de seus paradigmas" (AMORIM, 2017, p.516). No mesmo sentido:

Cada nova tecnologia tem o potencial de criar novos problemas e novas formas de solucionar os conflitos. A tecnologia tem transformado a forma como as pessoas se comunicam. Há 30 anos, $50 \%$ da população nunca havia feito uma ligação telefônica. [...] A invenção do carro criou disputas de seguro de acidentes, os telefones criaram novos conflitos relacionados a ligações indesejadas. As inovações mudam aspectos sociais das pessoas, assim como as maneiras como alguns conflitos são abordados (ECKSCHMIDT, 2016, p.63-4).

Nesse diapasão, a evolução digital deu origem às ODRs (Online Dispute Resolution), ou resolução de disputa online, que são métodos de solução de conflitos servidos de

\footnotetext{
${ }^{2}$ CNJ - CONSELHO NACIONAL DE JUSTIÇA. Justiça em Números 2018: ano-base 2017/Conselho Nacional de Justiça - Brasília: CNJ, 2018. Disponível em: http://cnj.jus.br/publicacoes. Acesso em: 21.ago.2019.
} 
tecnologia, com maior acessibilidade e dotados de melhoria de controle do ambiente, bem como aferição mais assertiva de resultados e organização, em função da prerrogativa do uso do Big Data, que, por sua vez, é um conjunto de dados que a cada milésimo de segundo são inseridos novos, e consequentemente implicando em uma inimaginável quantidade de informações, em crescimento permanentemente (DAVENPORT, 2012, p. 43-6).

A resolução online de conflitos ocorre total ou parcialmente no ciberespaço (GOODMAN, 2003, p. 02), o qual é definido por Pierre Lévy (1999, p. 92), como o "espaço de comunicação aberto pela interconexão mundial de computadores e das memórias dos computadores."

Na resolução de disputa online, ao invés das partes se reunirem em lugar físico para dirimir um conflito, estas podem se valer da tecnologia, até mesmo por meio da utilização de dispositivos móveis, para discutirem em salas virtuais e resolverem uma situação de forma mais inteligível, prática e econômica, com o privilégio de que o acordo elaborado neste ambiente poderá ser cumprido de forma voluntária e, portanto, amistosa.

Deste modo, temos que ODR é a resolução de controvérsias por meio da qual tecnologias de informação e comunicação não se limitam a substituir canais de comunicação tradicionais, mas agem como vetores para oferecer às partes ambientes e procedimentos ausentes em mecanismos convencionais de dirimir conflitos (ARBIX, 2017, p. 214). Tais soluções seriam "uma nova porta" para solucionar conflitos que talvez não possam ser dirimidos por mecanismos tradicionais de resolução de controvérsias (ARBIX, 2017, p. 214).

Assim sendo, é imperioso elucidar a importância da resolução de disputas online e quais as conveniências e proveitos para quem a utiliza na atualidade, visto que a sociedade contemporânea, cada vez mais virtual, está voltada para criação de soluções preventivas e ágeis que preservem o mercado digital, e, ainda, evitem que os conflitos de interesse corriqueiros sejam submetidos à máquina judiciária, a qual demanda gastos além de lapso temporal para alcance de uma solução efetiva.

\section{Origem da resolução de conflito online e conceituação}


Primordialmente, cumpre clarificar o nascedouro da resolução do conflito online no mundo, que teve como plataforma precursora a Virtual Magistrate em 1996 nos Estados Unidos (PONTE, 2002, p. 56), ferramenta com função principal de dirimir os conflitos entre os usuários da internet e seus operadores. A parte preenchia um formulário limitado a duzentos caracteres das informações do conflito, e, uma vez aceita a proposta pela contraparte, a plataforma dispunha de até setenta e duas horas para julgar a demanda.

Nesse cenário, através do Ato 262 de 2001, a Suprema Corte de Michigan ${ }^{3}$ aprovou a legislação que estabeleceu o primeiro tribunal público e totalmente virtual dos Estados Unidos, prógono do caminho trilhado pelas ODRs naquele país.

De acordo com o ato, os juízes nomeados para serem integrantes do cybercourt deveriam ter experiência em litígio comercial ou interesse em tecnologia. A norma previa também que todas as ações instauradas no cybercourt poderiam ser conduzidas por meios de “comunicações eletrônicas”, que incluíam, mas não se limitavam, a conferências de vídeo e áudio e conferência na internet entre o juiz e pessoal do tribunal, testemunhas e outras pessoas necessárias ao processo ${ }^{4}$.

Desde então, a partir de 2005, a American Arbitration Association, através do Model Standards of Conduct of Mediators ${ }^{5}$, disponibiliza em sua plataforma on-line serviços de reclamações, promove transferência de documentos, serve como intermediária de eventuais pagamentos e acordos e escolhe árbitros neutros, dentre outras conveniências.

Na União Europeia, por sua vez, a Diretiva 2013/11/EU ${ }^{6}$ foi seguida pelo Regulamento (UE) 524/2013 do Parlamento Europeu e do Conselho, de 21 de maio de 2013,

\footnotetext{
${ }^{3}$ MICHIGAN. Act n. 262. 2001. Disponível em: http://www.legislature.mi.gov/documents/20012002/publicact/pdf/2001-PA-0262.pdf. Accesso em: 18.ago.2019.

${ }^{4}$ Act n. 262 de 2001 (Ibid.), Sec. 8015. "All matters heard in the cyber court shall be heard by means of electronic communications, including, but not limited to, video and audio conferencing and internet conferencing among the judge and court personnel, parties, witnesses, and other persons necessary to the proceeding." Disponível em: http://www.legislature.mi.gov/documents/2001-2002/publicact/pdf/2001-PA-0262.pdf. Acesso em: 18.ago.2018.

${ }^{5}$ AMERICAN BAR ASSOCIATION. Addressing Disputes in Electronic Commerce: Final Recommendations and Report of The American Bar Association's Task Force on Electronic Commerce and Alternative Dispute Resolution. Chicago: American Bar Association, 2002. Disponível em: https://www.americanbar.org/content/dam/aba/migrated/2011_build/dispute_resolution/model_standards_condu ct_april2007.pdf. Acesso em: 21.ago.2019.

${ }^{6}$ DIRETIVA 2013/11/UE DO PARLAMENTO EUROPEU E DO CONSELHO de 21 de maio de 2013 sobre a resolução alternativa de litígios de consumo, que altera o Regulamento (CE) n. ${ }^{\circ}$ 2006/2004 e a Diretiva
} 
sobre a resolução de litígios de consumo online, que criou a plataforma de resolução de litígios.

A plataforma supracitada, que está em vigor desde fevereiro de 2016, conservada e financiada pela Comissão Europeia, corresponde a um site interativo, acessível de forma eletrônica e gratuita em todas as línguas oficiais da UE. Na prática, o mecanismo configura um sistema ODR e assume uma posição intermediária entre o consumidor e comerciantes, recebendo reclamações de ambas as partes, permitindo-lhes que possam resolver eletronicamente os seus litígios através de procedimentos extrajudiciais conduzidos pelas entidades de Resolução Alternativa de Litígio (RAL) em cada Estado-membro.

Decerto, desde o início das atividades, os sistemas de online dispute resolution se dividem em dois grandes grupos distintos: um deles representados por ferramentas computacionais, tais como chats, e-mails, instant messaging, fóruns, vídeos e chamadas de telefone, videoconferência, as quais contam com a intervenção humana de um terceiro facilitador; e outro representado por sistemas automatizados (softwares e programas de computador) especializados na resolução objetiva de conflitos, programados com base na experiência multidisciplinar da ciência, valendo-se da matemática, filosofia, direito e, sobretudo, da inteligência artificial (CARNEIRO, 2014, p. 215).

Já no Brasil, considerando a litigiosidade como um fenômeno social que tem crescido vertiginosamente nas últimas décadas, é insipiente afirmar que com a adoção das práticas online de resolução de conflitos será possível minimizar os problemas do Poder Judiciário no país. Com o advento da Lei no 13.105/2015 (Novo Código de Processo Civil) ${ }^{7}$ e da Lei 13.140/2015 (Lei da Mediação) ${ }^{8}$, no entanto, o Brasil passou a reconhecer o instituto processual da mediação e das demais práticas de resolução consensual de conflitos, como legítimos instrumentos de pacificação social.

2009/22/CE. Disponível em: https://eur-lex.europa.eu/legal-content/PT/TXT/?uri=CELEX\%3A32013L0011. Acesso em: 21.ago.2019.

${ }^{7}$ LEI N ${ }^{\circ}$ 13105, DE 16 DE MARÇO DE 2015. Disponível em: http://www.planalto.gov.br/ccivil_03/_Ato20152018/2015/Lei/L13105.htm. Acesso em: 21.ago.2019.

${ }^{8}$ LEI N ${ }^{\circ}$ 13140, DE 26 DE JUNHO DE 2015. Disponível em: http://www.planalto.gov.br/ccivil_03/_Ato20152018/2015/Lei/L13140.htm. Acesso em: 21.ago.2019. 
Disponível no país desde 2015, a plataforma MOL (mediação online) é a primeira ferramenta do gênero no Brasil especializada na resolução, gestão e prevenção de conflitos para pessoas físicas, empresas e instituições. Com a adesão cada vez mais frequente de usuários, torna-se perceptível a celeridade dos resultados obtidos com questões tratadas por este canal, sendo que há demandas que demorariam meses para serem solucionadas no âmbito da Justiça comum e por vezes são resolvidas dentro de apenas uma semana.

Neste contexto, importante trazer outro conceito das chamadas ODRs:

\begin{abstract}
Os modos de Resolução Online de Litígios (Online Dispute Resolution - ODR) consistem, portanto, na utilização dos recursos da tecnologia para a Resolução Alternativa de Litígios - ADR, quer sejam estes decorrentes exclusivamente das relações jurídicas firmadas no ciberespaço, quer sejam originários de relações jurídicas constituídas no mundo dito "físico". Nesse sentido, ODR pode ser considerado espécie do gênero ADR. Mas seria demasiado simplista imaginar que os meios de Resolução Online Litígios sejam reduzidos a uma simples expressão dos meios de Resolução Alternativa de Controvérsias. As possibilidades de utilização da tecnologia para a resolução de litígios são imensas e envolvem questões complexas, tanto do ponto de vista teórico quanto sob o prisma tecnológico, como, por exemplo, a utilização de inteligência artificial para fornecer uma solução para o conflito. [...] Sob uma perspectiva mais pragmática, os sistemas informatizados e as plataformas de transmissão e recepção de dados constituem um terceiro interveniente no processo de conciliação, ou até mesmo podem constituir um quarto sujeito, nos casos da mediação e da arbitragem online (AMORIM, 2017, p. 515).
\end{abstract}

Em acepção paralela, importante relembrar que os métodos de resolução online de conflitos também são complementados pelas TICs - Tecnologias da Informação e Comunicação (CORTÉS, 2019, p.83), e se refere a este processo como ODR, quando ele ocorre majoritariamente online. Isto pode incluir a proposição do procedimento, o agendamento neutro da sessão, os processos de produção de provas, as oitivas, discussões e mesmo a entrega de decisão vinculante. A ODR é simplesmente um meio diferente de se solucionar conflitos, do início ao fim, enquanto ainda respeitando os princípios do devido processo (CORTÉS, 2019, p.53).

Por fim, das qualificações acima, é imperioso afirmar que os mecanismos de resolução de conflitos online podem adotar ferramentas que variam da negociação à mediação, em softwares projetados com diferentes níveis de automação. Sistemas baseados em negociação, por exemplo, não exigem qualquer tipo de intervenção humana e podem funcionar de forma totalmente automatizada, contando somente com a participação das partes 
diretamente envolvidas no conflito. Tal modelo funciona por meio do envio de propostas ou contrapropostas por intermédio do próprio sistema de ODR.

No entanto, o padrão de sistema acima descrito pode não se mostrar apropriado quando o conflito em questão é baseado tão somente na disputa de valores monetários ou caso a obtenção de um acordo pelo pagamento pecuniário determinar o objetivo principal. Por isto, se faz imprescindível ponderar neste artigo as formas mais eficientes de utilização do sistema ODR e até mesmo analisar em quais situações pode haver risco de sucesso no desfecho do conflito.

\section{Tipos de Solução Digital de Conflitos}

De acordo com o já mencionado anteriormente, com o advento da Sociedade da Informação e o incremento da tecnologia como facilitadora nesta nova modalidade de distribuição de valor, a ODR - online dispute resolution, é uma crescente forma de solução de conflitos na era digital, cujo uso vem aumentando consideravelmente, inclusive no Brasil.

Em tempos de uma Quarta Revolução Industrial, na qual tecnologias emergentes e inovações generalizadas são difundidas de maneira célere e ampla (SCHWAB, 2016, p. 19), a inovação colaborativa é um dos fatores principais para acompanhar esta nova forma de organização social, cada vez mais conectada. Em razão dos diferentes impactos econômicos decorrentes deste movimento, as empresas têm reformulado alguns modelos de negócio, de maneira a atender aos anseios sociais, em especial com relação ao melhor atendimento dos consumidores.

Este movimento, inclusive, já é bastante notado em âmbito nacional, inclusive no Poder Judiciário quando se fala em tentativa de solução de conflitos, que é algo inerente à vida em sociedade, posto que, nos dizeres de Christopher W. Moore, “desacordos e problemas podem surgir em quase todos os relacionamentos" (MOORE, 1998, p. 22). 
E neste contexto de uma sociedade cada vez mais interconectada, que, além dos conflitos tidos em situações corriqueiras, ainda possui outros novos advindos da grande transferência de dados entre seus indivíduos, verifica-se o aumento dos conflitos de interesses, e, consequentemente, de demandas judiciais.

De maneira a evitar um assoberbamento do Poder Judiciário, conforme criticado supra, bem como visando divulgar melhores práticas empresariais, novos modelos de negócio surgiram visando, justamente, aliar a tecnologia e a celeridade visando a diminuição de um passivo judicial.

E nesta onda, como já mencionado anteriormente, as ferramentas de soluções digitais de conflitos ganham cada vez mais espaço, em diversos formatos, haja vista sua peculiaridade em relação aos métodos tradicionais (mediação e arbitragem), em razão da não discussão do mérito do conflito.

Os métodos de solução digital de conflitos podem variar, tanto com relação à arquitetura da plataforma quanto com relação ao meio de solução de conflitos em si, i.e., os institutos tradicionais já presentes na sociedade.

No tocante à arquitetura da plataforma, temos a negociação digital integralmente automatizada, a mediação utilizando um software em conjunto com um terceiro facilitador imparcial e a mediação tradicional por meio de tecnologias online (GOODMAN, 2003, p.04).

Com relação à negociação digital integralmente automatizada, esta normalmente funciona como um ambiente completamente livre para negociação entre as partes; o sistema envia uma mensagem eletrônica automática para a parte, que pode manifestar interesse ou declinar da negociação. No caso de aceite, o qual é manifestado na própria plataforma, o próprio computador já estima uma média daquilo que está sendo negociado e informa as partes, bem como ulteriores andamentos (GOODMAN, 2003, p.02).

$\mathrm{Na}$ mediação realizada por meio de uma plataforma juntamente com um terceiro imparcial, este participa como um facilitador dos interesses das partes, tanto pessoal ou virtualmente, auxiliando a manifestação das vontades e identificando questões que podem obstaculizar a resolução da questão (GOODMAN, 2003, p.06) 
A mediação tradicional por meio do desenvolvimento de novas tecnologias, é um misto das duas arquiteturas anteriormente mencionadas, na qual há o uso de plataformas e mecanismos automatizados, para facilitar algumas fases da negociação, mas, também, de um terceiro imparcial, o qual revisa a reclamação verificando sua plausibilidade e eventual interesse da parte contrária em tentar resolver o conflito (GOODMAN, 2003, p.06).

No tocante aos institutos básicos normalmente utilizados na solução de conflitos, temos quatro opções comumente utilizadas na atualidade: a negociação automatizada e assistida, a mediação online, a arbitragem online e o ombudsman online (PORTO, 2017, p. 298).

A negociação, como já informado, pode ser automatizada ou assistida, dependendo da plataforma que a mesma é realizada, e ocorre sem que as parte conflitante contestem fatos ou responsabilidade por uma suposta falha negocial (PORTO, 2017, p. 299). Nesta modalidade, as plataformas apenas analisam o limite de negociação de cada uma das partes, analisando propostas e contrapropostas, as quais são mantidas ocultas durante o procedimento e apenas divulgadas em um determinado momento preestabelecido (BARTOLINI, 2004, p., 213).

Na mediação, como já mencionado, há a intervenção de um terceiro imparcial o qual coordena as manifestações de vontade das partes conflitantes, em determinada plataforma, para que se alcance uma melhor solução para a questão; a mediação trabalha com pessoas e não com casos, dando ênfase às suas habilidades e limitações e promovendo seu fortalecimento com indivíduos objetos de direitos e deveres (NETO, 2010, p. 29).

A arbitragem é um meio de solução de conflitos no qual as partes previamente convencionam não submeter ao Poder Judiciário eventuais litígios decorrentes de uma determinada relação jurídica; normalmente as partes já escolhem o profissional que será responsável pela análise da questão, e o árbitro possui especialidade naquela determinada matéria, no intuito de preservar a reputação mercadológica dos envolvidos (MAGALHAES, 2009, p. 33). Atualmente, existem plataformas de arbitragem online, cujo procedimento é determinado pelo tipo de cláusula compromissória, a vazia ou a cheia.

Por fim, ainda temos o último instituto básico de solução de conflitos que é ombudsman online, por meio do qual um ouvidor é inserido institucionalmente nas empresas 
e, por meio do recebimento de informações via canais diversos (e-mail, chat, mensagens etc), leva eventual insatisfação com relação à alguma situação, produto ou serviço, à patamares superiores. Neste tipo de solução de conflitos online, evita-se que efetivamente haja um litígio por meio da antecipação com relação à tentativa de solução da questão.

Desta feita, em razão do crescente desenvolvimento tecnológico na Sociedade da Informação, inúmeras plataformas e institutos de solução de conflitos tendem a surgir, bastando que a sociedade esteja devidamente preparada e consciente para permitir que tal facilidade também seja incluída mais frequentemente como uma forma de resolução de entraves, e, deste modo, desafogar o Poder Judiciário de algumas questões, viabilizando uma melhor análise das lides que lhe são submetidos diariamente, sem a pressão relativa ao alcance de metas.

\section{Solução digital de conflitos e o direito constitucional de acesso à Justiça}

Considerando alguns aspectos relativos à inacessibilidade do Poder Judiciário para certa parte da população, quer por questões financeiras, estruturais ou sociais, temos que as práticas conciliativas se apoiaram em três pilares, a racionalização na distribuição da justiça, a pacificação social e a colaboração do corpo social nos processos de solução de conflitos (GRINOVER, 2007, p. 04).

É incontestável o grande aumento de demandas que atualmente assola o Poder Judiciário, o qual, ainda, não possui a estrutura necessária para a análise de um caso concreto de maneira efetiva; ante a necessidade de alcance de metas estabelecidas pelo CNJ, evidente que quanto antes demandas forem encerradas, melhor a métrica daquele determinado Juízo.

Sem a pretensão de afastar a eficiência do Poder Judiciário Brasileiro, evidente que com sua atual estrutura, bem como em razão das crescente demandas, em especial no âmbito consumerista, aquele não tem condições dispender grande quantidade de tempo em alguns casos que já são corriqueiros; deixa-se de analisar a casuística para julgar de maneira padronizada determinados tipos de demanda consideradas como repetitivas, fato este que pode causar prejuízo para as partes envolvidas.

É fato notório que o acesso à justiça é um direito fundamental, previsto no artigo $5^{\circ}$, XXXI, da Constituição Federal, que prega que "a lei não excluirá da apreciação do Poder 
Judiciário lesão ou ameaça a direito." Sob este prisma, em uma interpretação literal do dispositivo legal, entende-se que todos os tipos de conflitos caracterizados por uma pretensão resistida, necessariamente deveriam ser submetidos ao Poder Judiciário.

No entanto, em razão dos aspectos anteriormente mencionados, relativos à falta de recursos financeiros e estruturais, aliados à parte burocrática, evidente que na atualidade uma nova roupagem deve ser atribuída à referido preceito constitucional.

Neste sentido, o direito constitucional do acesso à Justiça, deve ser interpretado de maneira ampla e, conforme manifestação de Watanabe (1988, p. 128): “a problemática do acesso à justiça não pode ser estuada nos acanhados limites dos órgãos judiciais já existentes. Não se trata apenas de possibilitar o acesso à justiça enquanto instituição estatal, e sim de viabilizar o acesso à ordem jurídica justa."

Deste modo, o acesso à Justiça não deve ser resumido ao singelo aceso ao Poder Judiciário, mas, sim, refletido na garantia universal de que a solução dos conflitos seja acessível a todos os cidadão, independentemente de classe social, dando respostas às demandas em tempo razoável e proporcionando aos interessados a justiça social (MARASCA, 2007, p. 40).

Justamente em razão da necessidade de se alcançar uma justiça social efetiva, é que se buscou, por meio da exploração de meios privados ou informais, novos mecanismos de solução de conflitos:

\footnotetext{
Inicialmente, como já assinalamos, esse enfoque encoraja a exploração de uma ampla variedade de reformas, incluindo alterações nas formas de procedimento, mudanças na estrutura dos tribunais ou a criação de novos tribunais, o uso de pessoas leigas ou paraprofissionais, tanto como juízes quanto como defensores, modificações no direito substantivo destinadas a evitar litígios ou facilitar sua solução e a utilização de mecanismos privados ou informais de solução dos litígios. (CAPPELLETTI; GARTH, 1988, p. 70-1).
}

Assim, com base em uma nova análise do direito fundamental ao acesso à Justiça, amoldada aos recentes e constantes avanços tecnológicos, verifica-se que os meios de solução online de conflitos podem ser considerados uma forma eficaz de tentativa de resolução de contendas, com o objetivo de alcançar uma justiça social.

Este novo formato de solução de conflitos pode ser utilizado para gerir tanto conflitos que tenham origem online quanto aqueles decorrentes de outras relações fora do ciberespaço, trazendo uma vantagem adicional na medida que eliminam o ajuizamento de potenciais demandas judiciais, antes mesmo do seu nascimento (no início do conflito), 
economizando valor para a máquina estatal, além de prover celeridade aos interessados (LIMA, 2016, p. 64).

Além da função social destes novos modelos de solução de conflitos, há de se descartar que estes têm para os Tribunais, enquanto política pública para o Poder Judiciário, uma forma de aprimorar a prestação jurisdicional, na qual o papel da informação será mais valorizado na prevenção dos conflitos do que em sua efetiva solução (KATSH, 2012, p. 307308).

Apesar da solução online de conflitos ser uma nova e potencial forma de resolver questões, importante salientar que tal movimento ainda padece de alguns obstáculos, eis que nem toda a população brasileira possui internet ou acessibilidade adequada aos meios digitais, motivo pelo qual alguns passos ainda devem ser tomados, em especial pelo Poder Público, para que a sociedade tenha garantido o acesso à Justiça de maneira efetiva, nos moldes constitucionais.

\section{Considerações finais}

Evidente que com o advento da Sociedade da Informação e o consequente surgimento de novas relações jurídicas, em especial no ambiente digital, aliada às novas tecnologias de informação e comunicação (TICs), também aumentaram os números de conflitos de interesses. Na análise realizada neste artigo restou clara importância e crescente desenvolvimento de novas tecnologias que adotam a solução online de conflitos, pautadas em uma interpretação extensiva do direito fundamental do acesso à Justiça, previsto na Carta Magna, visando a busca de uma justiça social efetiva.

Por meio de um breve panorama histórico, seguido do conceito de ODR, salientou-se a importância da adoção de novas modalidades de solução de conflitos, em especial no mundo virtual, visando o fomento de políticas públicas, bem como da efetividade do acesso à Justiça, amoldado à nova realidade social.

O artigo também trouxe algumas formas de solução online de conflitos, classificadas tanto com relação à arquitetura da plataforma, quanto no tocante aos meios mais utilizados para resolver conflitos de interesses, as quais não são exaurientes, considerando o célere desenvolvimento tecnológico. 
Reforçou-se, também, que no Brasil o movimento pela adesão à esta nova modalidade de solução de conflitos é crescente, mas que ainda prescinde de uma atuação mais concentrada do Poder Público para permitir uma ampla acessibilidade dos cidadãos à internet, e, consequentemente, dar voz ao preceito constitucional do acesso à Justiça, visando a solução rápida, ágil e adequada de contendas alcançando, efetivamente, a justiça social.

\section{Referências Bibliográficas}

AMORIM, Fernando Sérgio Tenório de. A resolução online de litígios (ODR) de baixa intensidade: perspectivas para a ordem jurídica brasileira. Pensar: Revista de Ciências Jurídicas, Fortaleza, CE, 2017, v. 22, n. 2, p. 514-539.

ANDRIGHI, Fátima Nancy. Os métodos alternativos de resolução de litígios e o direito da internet: perspectivas no Brasil. BDJUR, Palestra proferida na Conferência Interamericana de Arbitragem Direito na Internet, promovida pelo Instituto Arbiter e Instituto Brasileiro de Política, Direito e Informática. Recife, 2005.

ARBIX, Daniel do Amaral. Resolução Online de Controvérsias. Intelecto Editora, São Paulo, 2017, p. 214.

BARTOLINI, Claudio; PREIST, Chris; JENNINGS, Nicholas R. A software framework for automated negotiation. International Workshop on Software Engineering for Large-Scale Multi-agent Systems. Springer, Berlin, Heidelberg, 2004. p. 213-235.

BAUMAN, Zygmunt. Medo líquido. Rio de Janeiro: Jorge Zahar, 2008.

CAPPELlETTI, Mauro; GARTH, Bryant. Acesso à justiça. Trad. Ellen Gracie Northfleet. Porto Alegre: Fabris, 1988.

CARNEIRO, Davide; NOVAIS, Paulo; ANDRADE, Francisco; ZELEZNIKOW, John; NEVES, José. Online dispute resolution: an artificial intelligence perspective. Artificial Intelligence Review, 2014, Vol. 41(2). p. 215. 
CORTÉS, Pablo. Online Dispute Resolution for Consumers in the European Union. New York: $\quad$ Routledge, $2011 . \quad$ Disponível em: http://www.oapen.org/viewer/web/viewer.html?file=http://www.oapen.org/document/391038. Acesso em: 21.ago.2019.

DAVENPORT, T. H; BART, P.; BEAN, R. How Big Data is Different. MIT Sloan Management Review, n.30 July, p. 43-6, 2012.

ECKSCHMIDT, Thomas; MAGALHÃES, Mario E. S.; MUHR, Diana. Do conflito ao acordo na era digital: meios eletrônicos para solução de conflitos - MESC. 2 ed. Curitiba: Doyen, 2016, p.63-64.

GOODMAN, Joseph W. The Pros and Cons of Online Dispute Resolution: An Assessment of Cyber-Mediation Websites. Duke Law \& Technology Review, Durham, v. 2, n. 1, p.0-0. Aug. 2003. Disponível em: http://scholarship.law.duke.edu/dltr/vol2/iss1/2. Acesso em: 30.ago.2019.

GRINOVER, Ada Pellegrini. Os fundamentos da Justiça Conciliativa in Mediação e gerenciamento do processo: revolução na prestação jurisdicional: guia prático para a instalação do setor de conciliação e mediação. São Paulo: Atlas, 2007.

JUNIOR, Vanderlei Freitas Nascimento. A evolução dos métodos alternativos de resolução de conflitos em ambiente virtual: online dispute resolution. Revista Eletrônica da Faculdade de Direito de Franca, v. 12, n. 1, p. 265-282, 2017.

KATSH, Ethan. ODR: a look at history. In: WAHAB, Mohamed S. Abdel; KATSH, Ethan e RAINEY, Daniel (Eds). Online dispute resolution: theory and practice. A treatise on technology and dispute resolution. The Hague: Eleven International, 2012.

LÉVY, Pierre. Cibercultura. São Paulo: 34, 1999.

LIMA, Gabriela Vasconcelos; FEITOSA, Gustavo Raposo Pereira. Online dispute resolution (ODR): a solução de conflitos e as novas tecnologias. Revista do Direito, v. 3, n. 50, p. 53-70, 2016.

MAGALHÃES, Rodrigo Almeida; SARAIVA, Marina de Souza. Arbitragem Eletrônica. Scientia Iuris, Londrina, v. 23, n. 2, p. 26-41, jul. 2019. DOI: 10.5433/21788189.2019v23n2p26. ISSN: 2178-8189. 
MARASCA, Elisângela Nedel. Meios alternativos de solução de conflitos como forma de acesso à justiça e efetivação da cidadania. Revista Direito em Debate, v. 16, n. 27-28, 2007.

MOORE, Christopher W. O processo de mediação: estratégias práticas para resolução de conflitos. Tradução de Magda França Lopes. Porto Alegre: Artmed, 1998.

NETO, Adolfo Braga. Mediação de conflitos: princípios e norteadores. Revista da Faculdade de Direito UniRitter, n. 11, p. 29-46, 2010.

PONTE, Lucille. The Michigan Cyber Court: a bold experiment in the development of the First Public Virtual Courthouse. North Carolina Journal Of Law \& Technology. Chapel Hill, v. 4, n. 1, pp. 51-92, 2002. pp. 56 e 57. Cf. também: FRIEDMAN, George H; GELMANN, Robert. An information superhighway "on ramp" for alternative dispute resolution. New York State Bar Journal. New York, v. 68, n. 4, pp. 38-42, 1996.

PORTO, Antônio José Maristrello; NOGUEIRA, Rafaela; DE CASTRO QUIRINO, Carina. Resolução de conflitos on-line no Brasil: um mecanismo em construção. Revista dos Tribunais. v. 114, p. 298, 2017.

SCHWAB, Klaus. A Quarta Revolução Industrial. São Paulo: Edipro, 2016.

WATANABE, Kazuo. Acesso à justiça e a sociedade moderna. In: GRINOVER, Ada Pellegrini et al (Coord.). Participação e processo. São Paulo: Revista dos Tribunais, 1988.

\section{Websites consultados}

BRASIL. CNJ - Conselho Nacional de Justiça. Justiça em Números 2018: ano-base 2017/Conselho Nacional de Justiça - Brasília: CNJ, 2018. Disponível em: http://cnj.jus.br/publicacoes. Acesso em: 21.ago.2019.

BRASIL. Lei $n^{o}$ 13.105, de 16 de março de 2015. Disponível em: http://www.planalto.gov.br/ccivil_03/_Ato2015-2018/2015/Lei/L13105.htm. Acesso em: 21.ago.2019. 
BRASIL. Lei $n^{o}$ 13.140, de 26 de junho de 2015. Disponível em: http://www.planalto.gov.br/ccivil_03/_Ato2015-2018/2015/Lei/L13140.htm. Acesso em: 21.ago.2019.

ESTADOS UNIDOS. ACT n. 262 de 2001. Disponível em: http://www.legislature.mi.gov/documents/2001-2002/publicact/pdf/2001-PA-0262.pdf. Acesso em: 18.ago.2019.

ESTADOS UNIDOS. American Bar Association. Addressing Disputes in Electronic Commerce: Final Recommendations and Report of The American Bar Association's Task Force on Electronic Commerce and Alternative Dispute Resolution. Chicago: American Bar Association, 2002. Disponível em: https://www.americanbar.org/content/dam/aba/migrated/2011_build/dispute_resolution/model _standards_conduct_april2007.pdf. Acesso em: 21.ago.2019.

ESTADOS UNIDOS. Michigan. Act n. 262. 2001. Disponível em: http://www.legislature.mi.gov/documents/2001-2002/publicact/pdf/2001-PA-0262.pdf. Acesso em: 18.ago.2019.

UNIÃO EUROPEIA. Diretiva 2013/11/EU do Parlamento Europeu e do Conselho de 21 de maio de 2013 sobre a resolução alternativa de litígios de consumo, que altera o Regulamento (CE) n. ${ }^{\circ}$ 2006/2004 e a Diretiva 2009/22/CE. Disponível em: https://eur-lex.europa.eu/legalcontent/PT/TXT/?uri=CELEX\%3A32013L0011. Acesso em: 21.ago.2019. 